\title{
Administration of Thimerosal to Infant Rats Increases Overflow of Glutamate and Aspartate in the Prefrontal Cortex: Protective Role of Dehydroepiandrosterone Sulfate
}

\author{
Michalina Duszczyk-Budhathoki • Mieszko Olczak • \\ Malgorzata Lehner • Maria Dorota Majewska
}

Received: 11 August 2011/Revised: 27 September 2011/ Accepted: 4 October 2011/Published online: 21 October 2011

(C) The Author(s) 2011. This article is published with open access at Springerlink.com

\begin{abstract}
Thimerosal, a mercury-containing vaccine preservative, is a suspected factor in the etiology of neurodevelopmental disorders. We previously showed that its administration to infant rats causes behavioral, neurochemical and neuropathological abnormalities similar to those present in autism. Here we examined, using microdialysis, the effect of thimerosal on extracellular levels of neuroactive amino acids in the rat prefrontal cortex (PFC). Thimerosal administration (4 injections, i.m., $240 \mu \mathrm{g} \mathrm{Hg}$ / $\mathrm{kg}$ on postnatal days $7,9,11,15)$ induced lasting changes in amino acid overflow: an increase of glutamate and aspartate accompanied by a decrease of glycine and alanine; measured 10-14 weeks after the injections. Four injections of thimerosal at a dose of $12.5 \mu \mathrm{g} \mathrm{Hg} / \mathrm{kg}$ did not alter glutamate and aspartate concentrations at microdialysis time (but based on thimerosal pharmacokinetics, could have been effective soon after its injection). Application of thimerosal to the PFC in perfusion fluid evoked a
\end{abstract}

M. Duszczyk-Budhathoki · M. Olczak · M. D. Majewska ( $ه)$ Marie Curie Chairs Program at the Department of Pharmacology and Physiology of the Nervous System, Institute of Psychiatry and Neurology, 02-957 Warsaw, Poland

e-mail: mdmajewska@gmail.com

M. Olczak

Department of Forensic Medicine, Medical University of Warsaw, Oczki 1 str., 02-007 Warsaw, Poland

M. Lehner

Department of Neurochemistry, Institute of Psychiatry and Neurology, 02-957 Warsaw, Poland

M. D. Majewska

Department of Biology and Environmental Science,

University of Cardinal Stefan Wyszynski, Wóycickiego Str. 1/3,

01-815 Warsaw, Poland rapid increase of glutamate overflow. Coadministration of the neurosteroid, dehydroepiandrosterone sulfate (DHEAS; $80 \mathrm{mg} / \mathrm{kg}$; i.p.) prevented the thimerosal effect on glutamate and aspartate; the steroid alone had no influence on these amino acids. Coapplication of DHEAS with thimerosal in perfusion fluid also blocked the acute action of thimerosal on glutamate. In contrast, DHEAS alone reduced overflow of glycine and alanine, somewhat potentiating the thimerosal effect on these amino acids. Since excessive accumulation of extracellular glutamate is linked with excitotoxicity, our data imply that neonatal exposure to thimerosal-containing vaccines might induce excitotoxic brain injuries, leading to neurodevelopmental disorders. DHEAS may partially protect against mercurials-induced neurotoxicity.

Keywords Thimerosal - Glutamate - Amino acids · Microdialysis · DHEAS

\section{Introduction}

Thimerosal, an organomercurial (THIM; sodium ethylmercurithiosalicylate), has been used as a preservative in liquid medicinal products, including pediatric vaccines, for decades without being adequately tested for safety in developing organisms. THIM, which contains approximately $49 \%$ mercury by weight and is composed of ethylmercury (EtHg) and thiosalicylic acid, is metabolized in the body to EtHg and further to inorganic forms of mercury [1]. Previous studies reported that THIM administration to rats leads to accumulation of mercury in the liver, kidneys and the brain, where it may produce toxic effects [2-6]. Although THIM was withdrawn from use in primary pediatric vaccines in most developed countries, it is still 
present in vaccines intended for children and pregnant women in developing countries [7-9].

Most guidelines for the medical use of THIM are based on studies evaluating the toxicity of methylmercury (MeHg), which has been studied more extensively. Ethylmercury and $\mathrm{MeHg}$ appear to be similar with respect to their initial distribution to the blood compartment, fecal excretion and pharmacodynamics. Nevertheless, there are some differences between them in tissue deposition and the rate of transformation to inorganic mercury forms $[3,10$, 11]. All mercurials, including THIM, are known to be neurotoxic, especially during early brain development [1214]. The neurotoxic actions of postnatally administered THIM were shown in mice and hamsters $[15,16]$. Our earlier studies documented that injections of THIM (i.m.) at vaccine-level doses or higher to rat neonates decreases viability of neurons and astrocytes in several brain regions, disrupts opioid and dopamine systems and induces behavioral deficits, which resemble the symptoms of autism [4, 17-19]. Neurotoxic effects were also shown in infant monkeys exposed to a THIM-containing vaccine (TCV) [20, 21]. In vitro studies revealed that incubation of neurons with THIM at nanomolar or micromolar concentrations leads to their death [22-25]. Neurotoxicity of THIM is aggravated by its action depleting intracellular glutathione-the peptide neuroprotective against metal toxicity [13].

Some epidemiological studies reported that infant exposure to TCVs is associated with neurodevelopmental disorders, including autism [7, 26-29]. Despite the growing number of studies documenting the neurotoxicity of THIM in developing organisms, research in this area is still fragmentary and controversial, demanding more wideranging investigations to reach a consensus regarding its postulated link with neurodevelopmental disorders. Research is also needed to fully explain the complex neurochemical mechanisms of THIM/mercurials-induced neurotoxicity.

In contrast to THIM, MeHg has been studied more comprehensively and is well-known as a neurotoxic substance [30, 31]. Based on similarities between EtHg and $\mathrm{MeHg}$ with regard to chemistry, tissue distribution and pharmacodynamics, the toxic effects of EtHg are believed to be analogous to those of $\mathrm{MeHg}[2,3]$. One of the hypotheses referring to the neurotoxicity of mercurials is linked with excitotoxicity. By inhibiting glutamate uptake in astrocytes and diminishing the activity of glutamine synthetase, mercurials can induce extracellular accumulation of glutamate, which can exert excitotoxic actions in neurons [32-34].

Because MeHg has been shown to augment overflow of glutamate in the brain [35], we were inquiring if THIM, administered subchronically and acutely to rats, has a similar effect. The present study aimed to: (1) evaluate the long-term effects of THIM administration to neonatal rats on extracellular levels of neuroactive amino acids (glutamate, aspartate, glycine, GABA and alanine) in the PFC; and (2) assess the acute effect on these amino acids when THIM is administered directly to the brain. In addition (3) we examined the potential modulatory effects of the adrenal steroid hormone, dehydroepiandrosterone sulfate (DHEAS), which is also a neurosteroid produced in the brain [36, 37], where it modulates neurotransmission of GABA and glutamate [38-40], influences the activity of neuronal calcium channels [41], and acts as neuroprotective neurohormone [42-44]. Learning about neurochemical mechanisms, which underlie the developmental neurotoxicity of THIM is essential, because TCVs continue to be used in many countries, potentially damaging the health of children. Examining the interactions between THIM and a neuroactive steroid-known to be altered in many neurological disorders-may aid the understanding of distinct vulnerabilities of individuals to mercurial-induced neurotoxicity and contribute to unraveling the complex biological processes involved in the pathogenesis of autism and other neurodevelopmental disorders. In the long run, such studies may assist the development of effective treatments for these disorders.

\section{Experimental Methods and Statistics}

\section{Animals, Chemicals, Experimental Design}

Pregnant female rats and adult male rats of the Wistar strain were supplied by the breeding house of the Medical Research Centre, Polish Academy of Science, Warsaw, Poland. The animals were kept in a room under standard conditions (12-12 h light-dark cycle with light on at 7:00 a.m.), at constant temperature $\left(21 \pm 2{ }^{\circ} \mathrm{C}\right)$ and $60 \%$ humidity. Laboratory chow and water were available ad libitum. The experiments were carried out during the light period. All tests were conducted according to the ethical standards laid down in respective Polish and European regulations (directive of 24 November 1986/609/ EEC). All experimental procedures were approved by the local Committee for Animal Care and Use at Warsaw Medical University. THIM and DHEAS were purchased from Sigma-Aldrich, Poland.

The microdialysis experiments measuring extracellular concentrations of amino acids in the PFC were conducted on two cohorts of male rats. One cohort received four i.m. THIM injections during the second postnatal week (neonatal THIM treatment model). Microdialysis was performed when these animals were 12-16 week old; in this group a delayed effect of THIM on extracellular brain 
levels of amino acids was examined $(\mathrm{N}=28)$. In a separate cohort of adult male rats (12-16 week old) an effect of THIM administered directly to the PFC was evaluated (acute THIM treatment model), $(\mathrm{N}=25)$.

\section{Treatment of Neonates with Thim and Neurosteroids}

Neonatal THIM treatment group: THIM dissolved in saline was injected in a volume of $50 \mu \mathrm{l}$ into the glutei maximi of newborn rats on postnatal days (PND): 7, 9, 11, and 15 in four equal-dose inoculations, based on the body weight. This treatment schedule was originally used in mice by Hornig and colleagues, imitating the US infant Vaccination Scheme of the year 2001 [15], and was subsequently employed by Laurente et al. [16] in the study on hamsters. We have also used this THIM treatment scheme in our previous studies in rats [4, 17-19]. The THIM doses per injection were: 12.5 or $240 \mu \mathrm{g} \mathrm{Hg} / \mathrm{kg}$. The lower dose is in the range of doses used in infant vaccinations in some countries $[4,15]$. The control group received saline injections. THIM-treated infant rats were allowed to grow with their mothers and litters. They were weaned on PND 28. Males were separated from females and allowed to reach maturity.

Thirty min before THIM administration, some animals received additional i.p. injections of DHEAS (dissolved in $50 \%$ water/saline in $50 \mu \mathrm{l}$ ) at a dose of $80 \mathrm{mg} / \mathrm{kg}$, while controls received saline-water injections. Rats from one litter received the same drug treatment; there were two litters per each type of treatment. The dosage of THIM was chosen in reference to our previously conducted behavioral and neuropathological studies [4, 17-19]. The dose of DHEAS was selected to attain its likely micromolar concentrations in the brain, which have been shown to affect neurotransmission [38-41].

\section{Implantation of Dialysis Probes and Microdialysis Procedure}

Probes (4 mm membrane length, Eicom, Kyoto, Japan; cut off $50 \mathrm{kDa}$, recovery for amino acids around $20 \%$ ) and a micro-syringe pump (BAS, USA) were used for the microdialysis experiment. The 12-16 week old male rats, which received neonatal injections of saline, THIM, DHEAS, or THIM combined with DHEAS were anesthetized with ketamine $(100 \mathrm{mg} / \mathrm{kg}$, i.p). The dialysis probe was fixed to the skull with anchor screws and dental acrylic cement. The probe was stereotaxically implanted into the PFC, taking bregma as a reference point (coordinates: +3.2 AP, 0.6 ML, 4.0 DV) [45]. Probes were inserted at least $24 \mathrm{~h}$ before the experiment to allow for equilibration of the extracellular environment around the probe tip.
Freely moving animals were kept in a microdialysis round bottom bowl with access to water and food ad libitum. Before implantation, the microdialysis probe was flushed with a Ringer's solution (B. Braun Medical Inc.) containing $(\mathrm{mM}): 147.2 \mathrm{NaCl}, 4.0 \mathrm{KCl}, 2.3 \mathrm{CaCl}_{2}$. The microdialysis sampling started after an initial $60 \mathrm{~min}$ stabilization of Ringer fluid perfusion at a flow rate of $2 \mu \mathrm{l} /$ min. Eight successive samples were collected manually over the 30 min periods.

A separate group of experimentally naïve 12-16 week old male Wistar rats was used in the acute THIM administration study. The procedures of microdialysis, type of probe and coordinates of implantation were the same as described above. The microdialysis sampling started after initial $60 \mathrm{~min}$ stabilization of Ringer fluid perfusion at a flow rate $2 \mu \mathrm{l} / \mathrm{min}$. First, three basal samples were collected manually over the 30 min periods. Subsequently, the solutions of THIM or $\mathrm{HgCl}_{2}$ (at 10 or $100 \mu \mathrm{M}$ concentrations) prepared in Ringer fluid were infused during the collection of the next three samples (90 min total). Finally, the initial perfusion solution was restored for the last two collected samples. In these (acute) experiments, we also tested the effects of DHEAS $(100 \mu \mathrm{M})$, coadministered with THIM in the perfusion solution.

The collected microdialysis samples were immediately frozen $\left(-70^{\circ} \mathrm{C}\right)$ at the end of each experimental session for later amino acid analyses. When the microdialysis experiment was terminated, the animals were sacrificed by an overdose of i.p. pentobarbital injections, and then decapitated. The brains were removed and sectioned to verify the probe placement. The extracellular concentrations of amino acids were determined in microdialysis samples by HPLC with electrochemical detection.

\section{HPLC Analysis}

The electrochemical detection system composed of an electrochemical detector with a flow cell (Decade II Antec Leyden, USA), Shimadzu CBM-20A controller system, LC-20AD pump, and CTO-20AC oven (Shimadzu, Germany) constituted the HPLC analytical system. The analysis of amino acids was performed using a Gemini C18 $5 \mu \mathrm{m}(150 \mathrm{~mm} \times 4.6 \mathrm{~mm})$ reversed phase column, protected by Security Guard cartridges (Phenomenex, USA). A high-density glassy carbon electrode (Decade II Antec Leyden, USA) was operated at $+0.85 \mathrm{~V}$. Preparation of the mobile phase and derivatizing agents were based on the method of Rowley et al. [46] with modifications. The mobile phase consisted of $26 \%$ methanol (Mallinckrodt Baker, The Netherlands), $40 \mathrm{mM}$ disodium phosphate and $0.8 \mathrm{mM}$ EDTA with, adjusted to $\mathrm{pH} 3.9$ with $0.2 \mathrm{M}$ citric acid (Sigma-Aldrich, Poland). It was filtered through 
$0.45 \mu \mathrm{m}$ filters (Millipore) and degassed for at least $15 \mathrm{~min}$ prior to use.

Stock solutions of amino acid standards were prepared in double deionized water and kept at $4^{\circ} \mathrm{C}$. Working solutions were prepared daily by dilutions of stock solutions. The OPA working solution was prepared as follows: $11 \mathrm{mg}$ of OPA (Fluka, USA) was dissolved in $0.25 \mathrm{ml}$ of $1 \mathrm{M} \mathrm{Na}_{2} \mathrm{SO}_{3}, 0.25 \mathrm{ml}$ absolute methanol and $0.45 \mathrm{ml}$ of $0.1 \mathrm{M}$ sodium tetraborate (Sigma-Aldrich, Poland) buffer adjusted to $\mathrm{pH} 10.4$ with $5 \mathrm{M}$ sodium hydroxide. This OPA stock reagent was stable for approximately 5 days and kept tightly sealed in a brown bottle at room temperature. The reaction of derivatization was performed at room temperature. $20 \mu \mathrm{l}$ of OPA working solution was added to $1 \mathrm{ml}$ of standard solution or dialysate, which was vortexed and reacted for $15 \mathrm{~min}$ in a polyethylene vial.

A rheodyne injection valve with $20 \mu 1$ sample loops was used to manually inject the samples. The column was maintained at a temperature of $30^{\circ} \mathrm{C}$. Compounds were eluted isocratically with mobile phase delivered at a flow rate of $0.6 \mathrm{ml} / \mathrm{min}$ over a $30 \mathrm{~min}$ runtime after an injection. Amino acids were identified by their characteristic retention time, comparing to retention times of sample peaks with those of their respective standards. Standard curves and stability data were generated using LC Solution software. The concentration of amino acids was calculated as $\mu \mathrm{M}$.

\section{Statistical Analysis}

The Statistica 8 software package for Windows (StatSoft, Tulsa, OK, USA) was used to analyze all experimental data. An analysis of variance (ANOVA) with repeated measure, followed by a post hoc Least Significant Differences Fisher's Test was employed. A probability value of $P<0.05$ was considered significant.

\section{Results}

Neonatal Treatment with THIM and DHEAS

The experiments measuring extracellular concentrations of glutamate, aspartate, GABA, glycine, and alanine in the PFC after neonatal administration of four doses of THIM with/or without DHEAS were conducted on five groups of rats: control/saline $(\mathrm{N}=6)$, THIM $12.5 \mu \mathrm{g} \mathrm{Hg} / \mathrm{kg}(\mathrm{N}=6)$, THIM $240 \mu \mathrm{g} \mathrm{Hg} / \mathrm{kg}(\mathrm{N}=6)$, DHEAS $80 \mathrm{mg} / \mathrm{kg}(\mathrm{N}=5)$, THIM $240 \mu \mathrm{g} \mathrm{Hg} / \mathrm{kg}+$ DHEAS $80 \mathrm{mg} / \mathrm{kg}(\mathrm{N}=5)$.

Neonatal THIM injections provoked a long-lasting increase in the extracellular levels of glutamate in the PFC (Fig. 1). A two way ANOVA with repeated measures revealed significant differences between the treatment

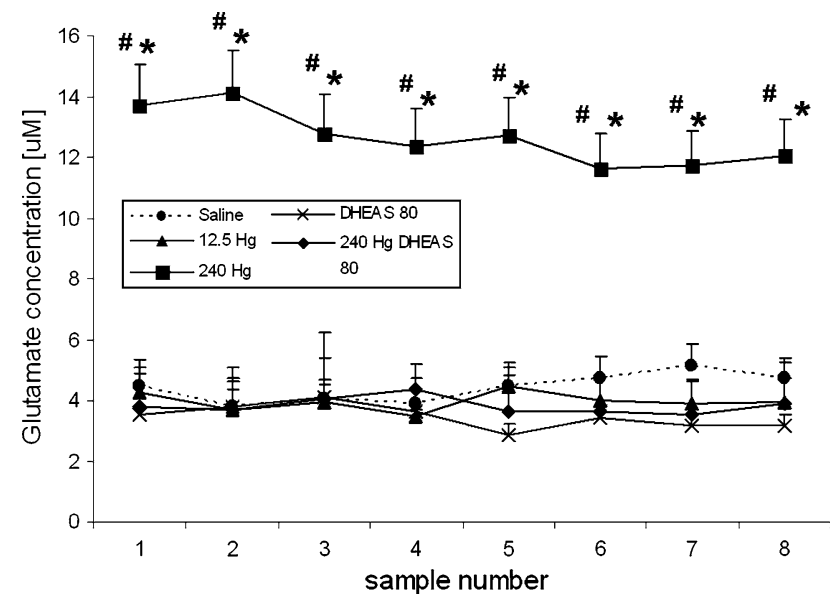

Fig. 1 Effect of neonatal administration of THIM and DHEAS on the concentration of extracellular glutamate in the PFC of adult rats. $Y$ axis: concentration of extracellular glutamate $(\mu \mathrm{M}) ; X$ axis: dialysate sample numbers. Figure legend describes treatment groups. The data are shown as means \pm SEM from six animals per group. Dialysates were collected at $30 \mathrm{~min}$ intervals in 8 time points. Four THIM injections at a dose of $240 \mu \mathrm{g} \mathrm{Hg} / \mathrm{kg}$ markedly increased the extracellular level of glutamate. DHEAS $(80 \mathrm{mg} / \mathrm{kg})$ prevented the effect of THIM, having per se no effect on glutamate concentration. Statistical significance compared with control $* * P<0.001$; compared with THIM $240 \mu \mathrm{g} \mathrm{Hg} / \mathrm{kg}+$ DHEAS ${ }^{\#} P<0.001$

groups: the effect of group $\mathrm{F}(4 ; 23)=5.9(P<0.001)$, no effect of sample $\mathrm{F}(7 ; 161)=0.32,(P=0.94)$ and non significant group/sample interaction $\mathrm{F}(28 ; 161)=0.69$, $(P=0.87)$. The post hoc analysis (LSD) revealed that the effect of a THIM dose of $240 \mu \mathrm{g} \mathrm{Hg} / \mathrm{kg}$ was statistically different from control $(P<0.001)$, but the effect of a $12.5 \mu \mathrm{g} \mathrm{Hg} / \mathrm{kg}$ dose was not significant $(P=0.92)$ in this measure. Administration of DHEAS alone to infant rats did not cause significant change in extracellular glutamate levels in the PFC of adult animals $(P=0.71)$. However, when this steroid was injected into rat neonates $30 \mathrm{~min}$ before THIM, it prevented the stimulating effect of this mercurial on glutamate overflow. The post hoc test revealed a statistical difference between the groups of THIM 240 and THIM $240 \mu \mathrm{g} \quad \mathrm{Hg} / \mathrm{kg}+$ DHEAS $(P<0.001)$.

The results in Fig. 2 illustrate the influence of neonatal administration of THIM and DHEAS, alone and in combination, on overflow of aspartate in the PFC. THIM treatment had a dose dependent effect on this amino acid. The two way ANOVA with repetitions indicated significant group differences in aspartate concentration: the effect of group $[\mathrm{F}(4 ; 23)=5.02, P=0.004]$, sample $[\mathrm{F}(7 ; 161)=6.7, P<0.001]$ and significant group/sample interaction $[\mathrm{F}(28 ; 161)=4.05, P<0.001]$. The post hoc analysis confirmed a significant effect for the THIM dose of $240 \mu \mathrm{g} \mathrm{Hg} / \mathrm{kg}$ (samples 4-7, $P<0.001$ ). Neonatal administration of a THIM dose of $12.5 \mu \mathrm{g} \mathrm{Hg} / \mathrm{kg}$ did not 


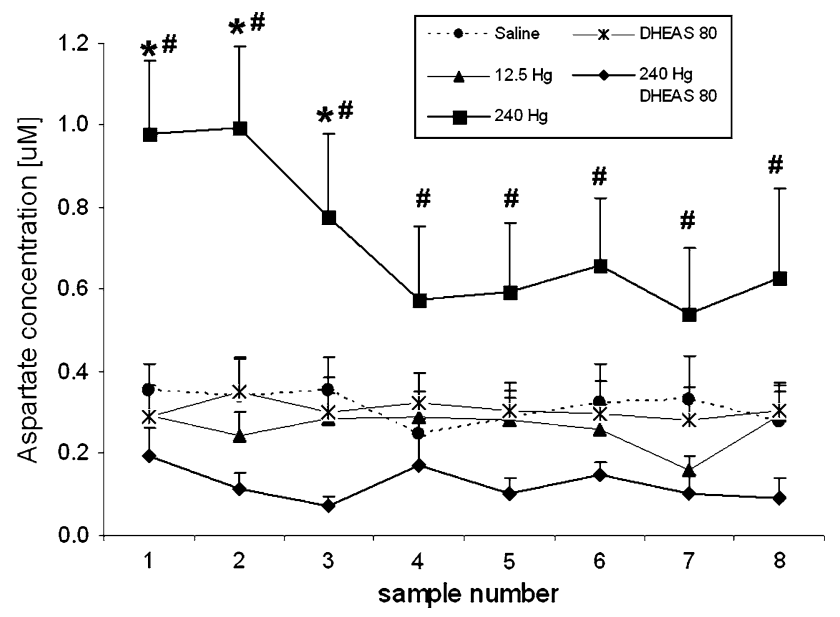

Fig. 2 Effect of neonatal administration of THIM and DHEAS on the concentrations of extracellular aspartate in the PFC of adult rats. $Y$ axis: concentration of extracellular aspartate $(\mu \mathrm{M}) ; X$ axis: dialysate sample number. Figure legend describes treatment groups. The data are shown as means \pm SEM from six animals per group. Dialysates were collected at $30 \mathrm{~min}$ intervals in 8 time points. THIM injections increased extracellular levels of aspartate; the effect was prevented by coadministration of DHEAS $(80 \mathrm{mg} / \mathrm{kg})$. Values statistically different from control $* P \leq 0.004$, and from THIM $240 \mu \mathrm{g} \mathrm{Hg} / \mathrm{kg}+$ DHEAS ${ }^{\#} P<0.001$

cause an elevation of extracellular aspartate in adult rats $(P=0.99)$. Coadministration of DHEAS $30 \mathrm{~min}$ before THIM prevented its effect on aspartate overflow. Post hoc analysis showed dissimilarity between the THIM 240 and THIM $240 \mu \mathrm{g} \mathrm{Hg} / \mathrm{kg}+$ DHEAS groups, confirming the significance of DHEAS action in preventing THIMinduced aspartate overflow $(P<0.001)$. The effects of DHEAS alone and saline were not statistically different $(P=0.68)$.

Neonatal THIM administration reduced the overflow of glycine in the rat PFC, thus having an opposite effect on this inhibitory amino acid than on the excitatory amino acids-glutamate and aspartate (Fig. 3). ANOVA demonstrated a significant group differences in glycine levels: effect of group $[\mathrm{F}(4 ; 23)=7.08, P<0.001]$, no effect of sample $[\mathrm{F}(7 ; 161)=0.66, P=0.7]$, and no significant group/sample interaction $[\mathrm{F}(28 ; 161)=0.75, P<0.8]$. Post hoc analysis confirmed a significant reduction of extracellular glycine concentration by a THIM dose of $12.5 \mu \mathrm{g} \mathrm{Hg} / \mathrm{kg}$ (samples $2-8),(P<0.001)$ and a dose of $240 \mu \mathrm{g} \mathrm{Hg} / \mathrm{kg}$ (samples $4-5),(P<0.05)$. Administration of DHEAS alone also decreased glycine levels $(P=0.001)$. There was no statistical difference between the effects of both THIM doses $(P=0.54)$ and DHEAS $(P=0.46)$, but the effect of combined THIM $240 \mu \mathrm{g} \mathrm{Hg} /$ $\mathrm{kg}+$ DHEAS was significantly greater than that of THIM alone $(P<0.05)$, indicating partly additive actions of both agents in reducing glycine outflow.

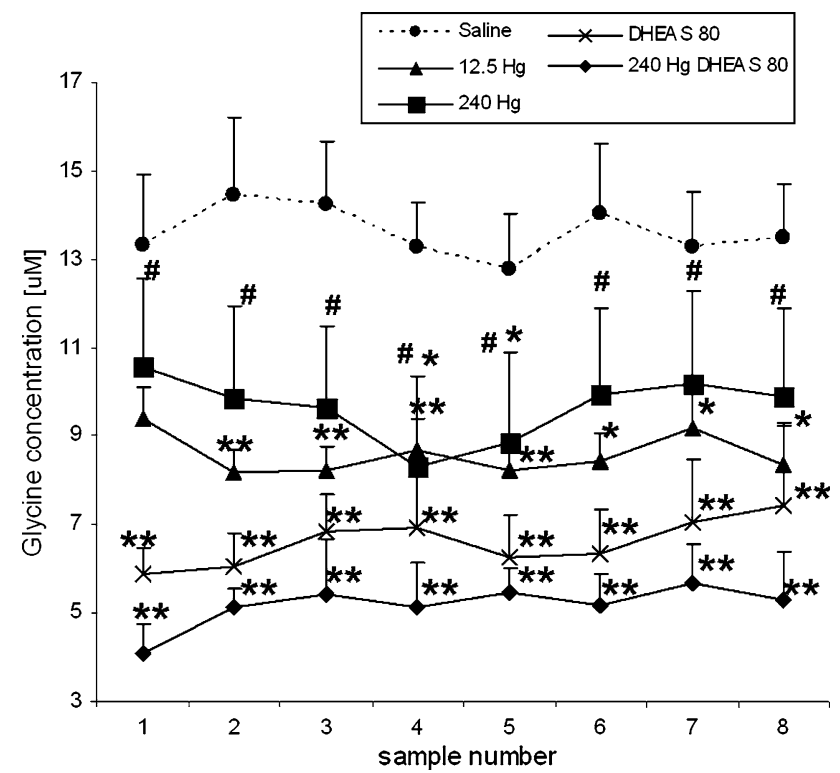

Fig. 3 The chronic effect of neonatal administration of THIM and DHEAS on extracellular levels of glycine in PFC. $Y$ axis: extracellular concentration of glycine $(\mu \mathrm{M}) ; X$ axis: dialysate sample number. Figure legend describes treatment groups. The data are shown as means \pm SEM from six animals per group. Dialysates were collected at 30 min intervals in 8 time points. Neonatal THIM administration decreased extracellular concentrations of glycine. DHEAS $(80 \mathrm{mg} / \mathrm{kg})$ alone also reduced glycine levels and DHEAS administered with THIM $(240 \mu \mathrm{g} \mathrm{Hg} / \mathrm{kg})$ decreased it further. Statistical significance compared with control: $* P<0.05, * * P<0.001$; compared with THIM $240 \mu \mathrm{g} \mathrm{Hg} / \mathrm{kg}+$ DHEAS ${ }^{\#} P<0.05$

THIM's effect on extracellular alanine was also distinct from its effect on glutamate or aspartate (Fig. 4). Two way ANOVA with repeated measures revealed: an effect of group $[\mathrm{F}(4 ; 23)=8.8, P=0.001]$, no effect of sample $[\mathrm{F}(7 ; 161)=1.65, P=0.12]$ and an effect of group/sample interaction $[\mathrm{F}(28 ; 161)=1.78, P=0.014]$. Post hoc analysis revealed a significant reduction of extracellular alanine in rats treated with a THIM dose of $240 \mu \mathrm{g} \mathrm{Hg} / \mathrm{kg}$ in comparisons with the saline group (samples 5-8, $P \leq 0.05)$, but not with a dose of $12.5 \mu \mathrm{g} \mathrm{Hg} / \mathrm{kg}$ $(P=0.73)$. DHEAS alone also significantly reduced levels of alanine with respect to saline $(P<0.05)$. In rats injected with a combination of THIM $240 \mu \mathrm{g} \mathrm{Hg} / \mathrm{kg}$ and DHEAS, the extracellular concentrations of alanine in the PFC were not lower than in animals treated with DHEAS alone, although they were significantly lower than in animals treated with saline $(P<0.05)$.

The basal extracellular concentration of GABA in microdialysis eluate (about $0.2 \mu \mathrm{M}$ ) was approximately 20 times lower than that of glutamate $(4 \mu \mathrm{M})$. THIM administration appeared to somewhat elevate the GABA level, while DHEAS slightly reduced it, but a two way ANOVA with repeated measures disclosed only a statistical tendency for THIM's effects on GABA levels: 


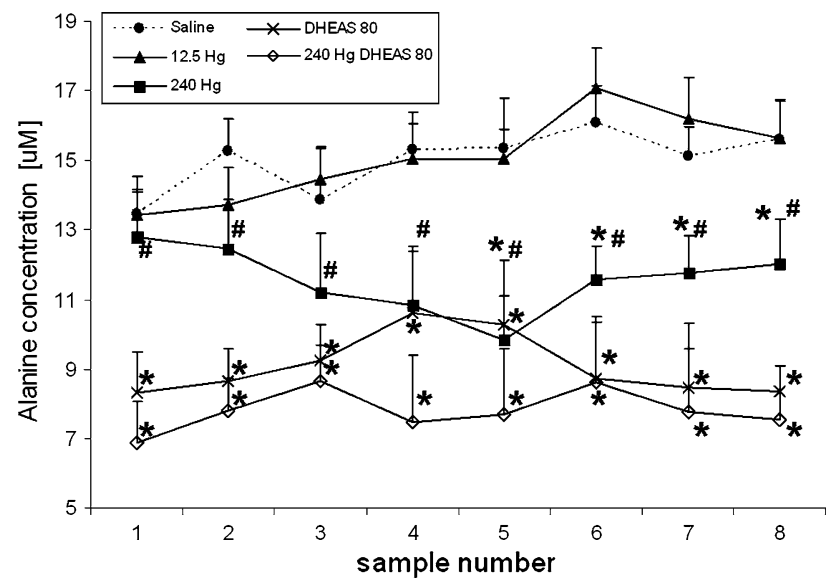

Fig. 4 Effect of neonatal administration of THIM and DHEAS on the concentrations of extracellular alanine in the PFC of adult rats. $Y$ axis: extracellular concentration of alanine $(\mu \mathrm{M}) ; X$ axis: dialysate sample number. Figure legend describes treatment groups. The data are shown as means \pm SEM from six animals per group. Dialysates were collected at $30 \mathrm{~min}$ intervals in 8 time points. THIM administration $(240 \mu \mathrm{g} \mathrm{Hg} / \mathrm{kg})$ reduced extracellular concentrations of alanine. Coadministration of DHEAS decreased it further. Statistical significance compared with control $* P<0.05$; compared with THIM $240 \mu \mathrm{g} \mathrm{Hg} / \mathrm{kg}+$ DHEAS ${ }^{\#} P<0.05$

[F $(4 ; 23)=2.61, \quad P=0.06], \quad$ no effect of sample $[\mathrm{F}(7 ; 161)=1.71, P=0.1]$ and no significant group/ sample interaction $[\mathrm{F}(28 ; 161)=1.36, P<0.12]$ (data not shown).

A summary of changes in the extracellular concentrations of all tested amino acids in the PFC of rats exposed to THIM during the neonatal period is shown in Table 1.

\section{Acute perfusion with THIM}

In order to examine direct effect of THIM and DHEAS on overflow of amino acids in the PFC, a separate set of experiments was performed with experimentally naïve adult rats which received both substances acutely in the perfusion fluid. The animals were divided into five groups based on the content of the perfusion fluid: control/saline

Table 1 Summary of changes in extracellular levels of neuroactive amino acids in the PFC induced by administration of THIM, DHEAS and their combination to infant rats

\begin{tabular}{llll}
\hline $\begin{array}{l}\text { Change in amino } \\
\text { acid overflow } \\
\text { comparing } \\
\text { to control }\end{array}$ & $\begin{array}{l}\text { THIM } \\
(240 \mu \mathrm{g} \\
\mathrm{Hg} / \mathrm{kg})\end{array}$ & $\begin{array}{l}\text { DHEAS } \\
(80 \mathrm{mg} / \mathrm{kg})\end{array}$ & THIM + DHEAS \\
\hline Glutamate & Increase & No change & No change \\
Aspartate & Increase & No change & No change \\
Glycine & Decrease & Decrease & Decrease \\
Alanine & Decrease & Decrease & Decrease \\
GABA & NS & NS & NS \\
\hline
\end{tabular}

$(\mathrm{n}=5)$, THIM $10 \mu \mathrm{M}(\mathrm{n}=5)$, THIM $100 \mu \mathrm{M}(\mathrm{n}=5)$, DHEAS $100 \mu \mathrm{M}(\mathrm{n}=5)$, THIM + DHEAS, $100 \mu \mathrm{M}$ each $(\mathrm{n}=5)$. It is important to note that THIM concentrations in the perfusion solutions are not equivalent to those attained in the perfused tissues, where they are limited by factors such as permeability and sorption by cellulose membranes of the microdialysis probes [47]. Therefore, the THIM concentrations which reach the tissue are probably significantly lower than those used in perfusion solutions. Likewise, it is expected that only a fraction of the DHEAS present in the perfusion fluid reaches the brain tissues. We have not measured the concentrations of both substances in the perfused tissue. These experiments were intended primarily to apprise qualitatively whether the effects of acute THIM administration directly to the brain are similar (or not) to those observed after its systemic administration to infant rats. Perfusion of the PFC with THIM induced rapid accumulation of extracellular glutamate in a dose-dependent manner (Fig. 5). A two way ANOVA with repeated measures (sample $\times$ group) revealed a significant effect of group $[\mathrm{F}(4 ; 20)=13.89, P<0.001]$, a significant effect of sample $[\mathrm{F}(6 ; 120)=12.69, P<0.001]$ and a significant sample/group interaction $[\mathrm{F}(24 ; 120)=11.91, P<0.001]$. The perfusion with $100 \mu \mathrm{M}$ THIM provoked a rapid raise of extracellular glutamate concentration to $192 \pm 18 \%$ of the basal level in sample 4 and to $293 \pm 68 \%$ in sample 6 . Post hoc analysis revealed a statistically significant difference between basal and $100 \mu \mathrm{M}$ THIM exposure for samples 4-6 $(P<0.001)$. Glutamate levels measured during the perfusion with $100 \mu \mathrm{M}$ THIM were also significantly different from those measured during THIMpostexposure $(P<0.001)$. An increase of glutamate overflow during perfusion with $10 \mu \mathrm{M}$ THIM, while noticeable, did not reach statistical significance $(P<0.07)$.

Coadministration of $100 \mu \mathrm{M}$ DHEAS with $100 \mu \mathrm{M}$ THIM during the perfusion period completely blocked the action of THIM on glutamate, while per se this steroid was without effect (Fig. 5). Post hoc analysis indicated significant difference between the group perfused with $100 \mu \mathrm{M}$ THIM and that perfused with $100 \mu \mathrm{M}$ THIM + DHEAS in the exposure period (samples $4-6 ; P<0.001$ ). There was no statistical difference between THIM + DHEAS and control $(P=0.58)$. Post hoc analysis also did not show dissimilarity between the groups DHEAS alone and THIM + DHEAS $(P=0.40)$, nor between DHEAS and control groups $(P=0.77)$. In dialysate probes from the PFC of rats perfused with THIM and DHEAS we also measured overflow of aspartate, glycine and alanine. Neither acutely administered THIM, nor DHEAS alone or in combination significantly altered extracellular levels of these amino acids.

Because THIM is metabolized in tissues to inorganic $\mathrm{Hg}$ species, we compared its effect on glutamate to that of 


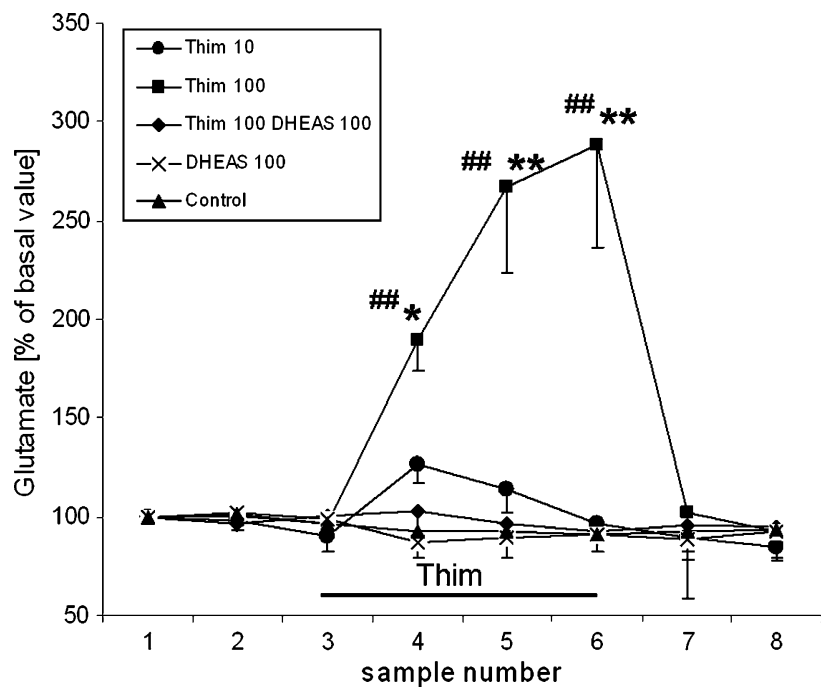

Fig. 5 Changes in extracellular levels of glutamate in the PFC during acute perfusion with THIM and DHEAS. $Y$ axis: change of extracellular glutamate expressed as $\%$ of basal value; $X$ axis: dialysate sample number. Samples 1-3 represent basal values. Samples 4-6 represent the period of exposure to $10 \mu \mathrm{M}$ THIM, $100 \mu \mathrm{M}$ TMIM, $100 \mu \mathrm{M}$ DHEAS, or $100 \mu \mathrm{M}$ THIM $+100 \mu \mathrm{M}$ DHEAS (all compounds were dissolved in the Ringer perfusion fluid). Samples 7-8 present the period of post drug exposure-perfusion with the Ringer solution only. Control group was perfused with Ringer solution. Individual samples were collected manually over periods of $30 \mathrm{~min}$ each; 8 samples per experimental animal were collected. Each point represents the mean \pm SEM from 5 animals per experimental group; $\mathrm{N}=25$. The values plotted were not corrected for recovery. Statistical significance compared with control ${ }^{*} P<0.05, * * P<0.001$; compared with $100 \mu \mathrm{M}$ THIM $+100 \mu \mathrm{M}$ DHEAS ${ }^{\# \#} P<0.001$

$\mathrm{HgCl}_{2}$. For this purpose we administered solutions of $10 \mu \mathrm{M} \mathrm{HgCl}_{2}(\mathrm{n}=4), 100 \mu \mathrm{M} \mathrm{HgCl}_{2}(\mathrm{n}=4)$, or saline $(\mathrm{n}=5)$ to the PFC in a manner identical to which THIM was administered. Brain perfusion with $\mathrm{HgCl}_{2}$ also augmented the overflow of glutamate (Fig. 6), but this mercurial appeared less potent than THIM, as at a $100 \mu \mathrm{M}$ concentration (in perfusate) it augmented the extracellular glutamate level maximally by about $40 \%$ above the baseline, while equimolar THIM elevated the glutamate level nearly by $200 \%$. The ANOVA with repeated measures revealed a significant effect of $\mathrm{HgCl}_{2}$ dose $[\mathrm{F}(2 ; 10)=$ 5.25; $(P<0.05)]$. Post hoc analysis showed a statistical difference between the basal and $100 \mu \mathrm{M} \mathrm{HgCl}_{2}$ exposures $(P=0.001)$.

\section{Discussion}

Ours is the first study - to the best of our knowledgedocumenting that administration of THIM to infant or adult rats disrupts the balance between the excitatory and inhibitory amino acids in the brain and that this effect is

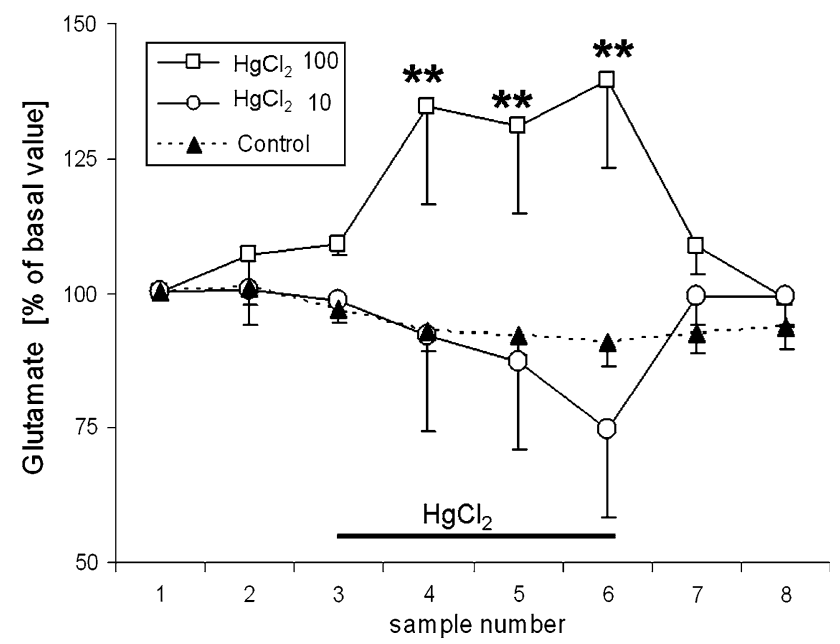

Fig. 6 Changes in extracellular glutamate in the PFC during perfusion with $\mathrm{HgCl}_{2} . Y$ axis: change of extracellular glutamate expressed as $\%$ of basal value; $X$ axis: dialysate sample number. First 3 samples constitute basal values. Samples 4-6 represent the exposure period to $10 \mu \mathrm{M}$ or $100 \mu \mathrm{M} \mathrm{HgCl} 2$ in the Ringer perfusion fluid, samples 7-8 represent the postexposure period. Control group was perfused with Ringer fluid only. Each point represents the mean \pm SEM from 4 to 5 animals; $N=13$. The values plotted were not corrected for recovery. Statistical significance compared with basal $* * P<0.001$

prevented by the neurosteroid, DHEAS. Repeated i.m. THIM injections to neonatal rats induced lasting elevation of extracellular concentrations of glutamate and aspartate, but decreased concentrations of glycine and alanine in the PFC. Coadministration to these animals of DHEAS, which per se did not alter glutamate and aspartate levels, prevented THIM's actions on these neurotransmitters. In contrast, DHEAS reduced the overflow of glycine and alanine, adding to THIM's effects on these amino acids. Acute, brief application of THIM in the perfusion fluid directly to the PFC in adult rats also induced a rapid increase of glutamate overflow without altering the levels of other amino acids. This effect was blocked by coadministration of DHEAS as well.

Qualitatively, the actions of THIM on brain glutamate were similar for the repeated neonatal exposure and acute intracerebral administration in adult rats, but there were important quantitative differences between them. In mature animals, THIM administration to the PFC induced a brief increase of glutamate overflow, which vanished after the mercurial was washed out, whereas in rats which received systemic THIM injections during the neonatal period, the overflow of glutamate was long lasting. This may be due to accumulation of mercury in the brains of neonatally THIMtreated rats and due to the greater vulnerability to mercurial neurotoxicity of immature animals. While discussing the potential mechanisms of THIM's actions on the brain neuroactive amino acids and their toxicological implications, 
it is important to take into account the effective concentrations and pharmacokinetics of this mercurial in the brain. The microdialysis experiments with rats treated with THIM during infancy were conducted 10 to 14 weeks after THIM administration. At that time, in animals which received four injections of THIM at doses of $12.5 \mu \mathrm{g}$ $\mathrm{Hg} / \mathrm{kg}$ - equivalent to doses used in some pediatric vaccines [4] - no significant changes in the overflow of glutamate, aspartate, or alanine were observed; only a reduction in glycine concentration was noted. In contrast, four injections of THIM at a dose of $240 \mu \mathrm{g} \mathrm{Hg} / \mathrm{kg}$ produced a profound, lasting rise in extracellular levels of glutamate and aspartate, and a reduction of glycine and alanine.

The pharmacokinetic studies in monkeys revealed that $\mathrm{Hg}$ from systemic THIM administration accumulates in the brain and remains there for months/years [3]. Our previous study showed that in the rat brain the $\mathrm{Hg}$ level peaks on day 4 after neonatal (i.m.) THIM injection, reaching 13-14\% of the initial concentration (calculated per body weight), and that half-life of THIM-Hg in the rat brain is approximately 8 days [4]. On day 30 after the injection, the amount of $\mathrm{Hg}$ remaining in the rat brain was about $10 \%$ of that from day 4. Based on these data, we can calculate that at the time of the microdialysis experiments (10-14 weeks after neonatal THIM injections; present study) the probable brain $\mathrm{Hg}$ concentrations in rats, which received four doses of $240 \mu \mathrm{g} \mathrm{Hg} / \mathrm{kg}$, were low nanomolar. Analogous $\mathrm{Hg}$ concentrations were likely to be present in the brains of rats which received four doses of $12.5 \mu \mathrm{g}$ THIM- $\mathrm{Hg} / \mathrm{kg}$ during the first days/weeks after the injections, suggesting that the lower THIM doses (used in the current study) could have also increased levels of excitatory amino acids shortly after THIM administration. This notion is supported by findings of ischemic-like neuropathological changes in the brains of rats which received this lower dose of THIM during the neonatal period [18]. In acute treatment experiments, perfusion with a THIM dose of $100 \mu \mathrm{M}$ induced a rapid raise of glutamate overflow during the perfusion period-which was gone after the mercurial wash out-while the perfusion with $10 \mu \mathrm{M}$ THIM did not have a significant effect. We have not measured $\mathrm{Hg}$ concentrations in the brain tissue of THIM-perfused rats. As mentioned in the Results, they are not the same as those present in the perfusion solutions, but most likely much lower. It is not clear at present, if persistent changes in the overflow of neuroactive amino acids in the brains of animals exposed to THIM during infancy resulted from a direct toxic effect of $\mathrm{Hg}$ on amino acid release, uptake, or metabolism in neurons and glia, or from developmental, neurotoxic modifications in the brain architecture and function which altered neurotransmission. Nonetheless, the transient nature of the changes observed after acute THIM administration in adult rats and apparent lack of residual effects on excitatory amino acids ten to fourteen weeks after neonatal exposure to lower doses of THIM, suggest that its effect on these neurotransmitters may be at least partially reversible after $\mathrm{Hg}$ clearance from the brain.

The pharmacodynamic mechanisms of THIM-induced changes in brain amino acids are probably complex, as mercurials interact with many functional proteins and cell structures, affecting various biological processes. They may involve effects on amino acid metabolism, synaptic and non synaptic release or uptake, altered function of enzymes, and changes in gene expression. It is intriguing that the neonatal THIM treatment caused prolonged alterations in the levels of several amino acids in the PFC, but the effect of brief THIM administration directly to the PFC was specific mainly to changes in glutamate. In another study, perfusion of medulla with a solution of $\mathrm{Hg}$ salt ( $p$-chloromercuriphenylsulphonic acid) was reported to augment the overflow of several amino acids [48]. The reason for this discrepancy remains to be clarified, but it could be due to differences in the chemical nature of the mercurial used, the brain regions studied, or other methodological distinctions. It is, however, not surprising to see a divergence in the metabolism, release or uptake of amino acids, which possess distinct neurochemical properties, are secreted from different cell populations under various physiological conditions, and undergo diverse metabolic pathways. In fact, in astrocytes mercurials were found to be less efficacious in inhibiting uptake of an inhibitory than an excitatory neurotransmitter [49].

In general, our findings are concordant with those of Hornig et al. [15], reporting changes in the glutamate system in neonatally THIM-exposed mice, and with data regarding the effects of $\mathrm{MeHg}$ on brain glutamate [33-35, 49, 50], which point to its extracellular built-up. Such mercurial-induced effects could ensue in part from inhibition of glutamate uptake by astrocytes [32, 33, 49], decline of activity of glutamine synthetase [34], or other forms of neurotransmitter release from intracellular pools [50]. Regardless of the mechanisms contributing to the described alterations in neuroactive amino acids in the brains of THIM-treated animals, they indicate a loss of balance between excitatory and inhibitory neurotransmitters, apparently leading to synergistic amplification of neuronal excitation. Glutamate - the main excitatory neurotransmitter in the brain-mediates processes associated with neuronal communication, regulation of brain development, determination of cell survival and differentiation, formation and elimination of synapses, among others. For these reasons, maintenance of glutamate homeostasis in the CNS is vital and its disturbance may have serious repercussions for brain development and functioning. Due to the excitatory properties of glutamate, large increase of its extracellular 
level may lead to excitotoxicity and neuronal damage, contributing to neurodegenerative disorders [51-53].

Mercurial-mediated neurotoxicity involves many neurochemical and cellular processes that engage glutamate, such as oxidative stress, mitochondrial damage, rise of intracellular $\mathrm{Ca}^{2+}$ and depletion of cellular glutathione [13, 54-58]. Mercurials have a high affinity for thiols, hence strongly react with the sulfhydryl groups of amino acids, peptides and proteins. Mercury-protein interactions seem to explain the inhibition of ion transporters, channels, receptors, or glutamate transporters [49, 59-61]. Such mechanisms certainly contribute to the neurotoxic actions of THIM [13, 25, 62]. Due to its lipophilicity THIM easily enters the brain, where it is converted to EtHg, and then to other mercury species $[1,3,11]$. In infants its passage to the brain is further facilitated by immaturity of the blood-brain barrier [63]. Since developing brains are hypersensitive to the neurotoxic actions of mercurials and excitotoxic stimulation [64, 65], a persistent rise of the extracellular glutamate level in brains of infant animals may lead to neurodegeneration. Such effects have been, in fact, documented in rats exposed in infancy to even low doses of THIM [18].

The cellular processes mediating THIM-induced decline in overflow of glycine and alanine are also unknown at present. In the brain stem and spinal cord neurons, glycine transporters are inhibited by mercurials [66]. If they function similarly in the PFC, one would expect to observe an increase of glycine overflow in this structure, but this was not the case in our experiments. However, "orphan transporters" selective for glycine, proline, alanine and leucine have been identified in synaptic vesicles of glutamatergic and GABAergic cortical neurons [67]. They may be regulated by different mechanisms and respond diversely to mercurials than the glycine transporters in spinal cord neurons.

The neurotoxicological consequences of THIM-mediated changes in the overflow of neuroactive amino acids are predictable. A rise of the synaptic concentrations of glutamate and aspartate and a decline of glycine and alanine may shift the balance in favor of neuronal stimulation, leading to excitotoxic neuronal injuries. Augmented activity of excitatory amino acids may also distort critical developmental processes in the brain, including survival and differentiation of neurons, apoptosis and formation of functional synapses, thus contributing to neurodevelopmental disorders. The roles of glycine and alanine in these phenomena may be ambiguous however. In the cortex of adult mammals these amino acids function mainly as inhibitory transmitters $[68,69]$, but in the neonate cortex glycine is excitatory, as it depolarizes neurons via strychnine-sensitive receptors [70]. Glycine also acts as coagonist of NMDA receptors, augmenting their excitatory function
[71]. In this context, the THIM-induced decrease of glycine overflow may be viewed as potentially protecting neurons from excessive stimulation, for it would diminish excitation via strychnine-sensitive receptors in the neonate cortex, and excitation via the NMDA receptors in adult animals.

The important novel finding of this study is that DHEAS prevents some of the THIM-induced changes in overflow of cortical amino acids. In the neonatal treatment model, pups received DHEAS injections 30 min before THIM. Microdialysis experiments showed that treatment with this steroid blocked the THIM effect on glutamate and aspartate. A similar effect was noted when DHEAS was coadministered with THIM in the perfusion fluid to the brain. DHEAS action on inhibitory amino acids was unlike that on glutamate, as this steroid alone diminished overflow of glycine and alanine and further enhanced the inhibitory effect of THIM on their release. This is additional evidence of a divergence of mechanisms regulating the transport of excitatory and inhibitory amino acids in the PFC.

DHEAS, a sulfated derivative of dehydroepiandrosterone, is the most abundant steroid hormone in blood of adult humans and a neurosteroid synthesized in the brain. DHEA and DHEAS, which are interconvertible in the body, have multiple functions in the CNS. DHEAS, in addition to acting as a regulator of gene expression, interacts with the $\mathrm{GABA}_{\mathrm{A}}, \mathrm{NMDA}$, and glycine receptors, thus modulating neurotransmission, influencing brain development and neuronal plasticity among other processes [37-41, 72]. DHEAS has also shown neuroprotective features in different models of brain injury [43, 73], and may guard neurons from the neurotoxic actions of excitatory amino acids [44, 74]. Our findings imply that it may as well protect against some aspects of mercurial neurotoxicity. It may bind to mercurials in a manner similar to that of spironolactone and other sulfur-containing steroids [75, 76], making them biologically less active. Alternatively, since some steroids (testosterone and cholesterol) augment the activity of glutamate/aspartate transporters in epithelial cells and primary cortical cultures [77, 78], DHEAS may act in a comparable way in neurons or glia, counteracting the effect of mercurials on these neurotransmitters.

In summary, the present study documents that exposure of infant rats to THIM perturbs the balance between excitatory and inhibitory amino acids in the brain, shifting it toward excessive neuroexcitation. DHEAS prevents some of these effects. Despite of intrinsic limitations, present findings have important clinical implications, as they provide a plausible mechanism, whereby THIM exerts neurotoxic effects in the brain. It is likely that this mercurial-still present in pediatric vaccines in many countries-causes a similar disturbance of excitatory and inhibitory neurotransmitters in the brains of human infants, 
leading to neurotoxicity, encephalopaties, and in consequence to neurodevelopmental disorders, including autism [7, 8, 20, 21, 26-29]. TCVs may lead to neurodegenerative diseases in adults as well. Another potential clinical significance of this study pertains to the protective effect of DHEAS. Augmented levels of androgens have been reported in the blood of autistic children [79] and we found elevated concentrations of many steroids, including DHEAS, in the saliva of such children (manuscript in preparation). While anomalous steroid levels certainly may disturb brain development, the present data suggest that they may also protect against some aspects of mercurialmediated neurotoxicity. On the whole, the current study provides further empirical evidence that exposure to THIM leads to neurotoxic changes in the developing brain, arguing for urgent and permanent removal of this preservative from all vaccines for children (and adults) since effective, less toxic and less costly alternatives are available. The stubborn insistence of some vaccine manufacturers and health agencies on continuation of use of this proven neurotoxin in vaccines is testimony of their disregard for both the health of young generations and for the environment.

Acknowledgments We are grateful to Ms. Alicja Sobolewska and Danuta Turzyńska for skillful technical assistance. This study is a part of the ASTER project, supported by the European Commission grant (MEXC-CT 2006-042371) and the supplemental funding from the Polish Ministry of Higher Education to Maria Dorota Majewska.

Conflict of interest None of the authors declares a conflict of interest.

Open Access This article is distributed under the terms of the Creative Commons Attribution Noncommercial License which permits any noncommercial use, distribution, and reproduction in any medium, provided the original author(s) and source are credited.

\section{References}

1. Qvarnström J, Lambertsson L, Havarinasab S, Hultman P, Frech W (2003) Determination of methylmercury, ethylmercury, and inorganic mercury in mouse tissues, following administration of thimerosal, by species-specific isotope dilution GC-inductively coupled plasma-MS. Anal Chem 75:4120-4124

2. Magos L, Brown AW, Sparrow S, Bailey E, Snowden RT, Skipp WR (1985) The comparative toxicology of ethyl- and methylmercury. Arch Toxicol 57:260-267

3. Burbacher TM, Shen DD, Liberato N, Grant KS, Cernichiari E, Clarkson T (2005) Comparison of blood and brain mercury levels in infant monkeys exposed to methylmercury or vaccines containing thimerosal. Environ Health Perspect 113:1015-1021

4. Olczak M, Duszczyk M, Mierzejewski P, Majewska MD (2009) Neonatal administration of a vaccine preservative, thimerosal, produces lasting impairment of nociception and apparent activation of opioid system in rats. Brain Res 1301:143-151
5. Rodrigues JL, Serpeloni JM, Batista BL, Souza SS, Barbosa F Jr (2010) Identification and distribution of mercury species in rat tissues following administration of thimerosal or methylmercury. Arch Toxicol 84:891-896

6. Minami T, Miyata E, Sakamoto Y, Kohama A, Yamazaki H, Ichida S (2009) Expression of metallothionein mRNAs on mouse cerebellum microglia cells by thimerosal and its metabolites. Toxicology 261:25-32

7. Geier DA, Geier MR (2006) A meta-analysis epidemiological assessment of neurodevelopmental disorders following vaccines administered from 1994 through 2000 in the United States. Neuro Endocrinol Lett 27:401-413

8. Majewska MD, Urbanowicz E, Rok-Bujko P, Namyslowska I, Mierzejewski P (2010) Age-dependent lower or higher levels of hair mercury in autistic children than in healthy controls. Acta Neurobiol Exp (Wars) 70:196-208

9. Dórea JG (2011) Integrating experimental (in vitro and in vivo) neurotoxicity studies of low-dose thimerosal relevant to vaccines. Neurochem Res 36:927-938

10. Harry GJ, Harris MW, Burka LT (2004) Mercury concentrations in brain and kidney following ethylmercury, methylmercury and Thimerosal administration to neonatal mice. Toxicol Lett 154: 183-189

11. Clarkson TW, Magos L (2006) The toxicology of mercury and its chemical compounds. Crit Rev Toxicol 36:609-662

12. Sanfeliu C, Sebastià J, Cristòfol R, Rodríguez-Farré E (2003) Neurotoxicity of organomercurial compounds. Neurotox Res 5: 283-305

13. James SJ, Slikker W 3rd, Melnyk S, New E, Pogribna M, Jernigan S (2005) Thimerosal neurotoxicity is associated with glutathione depletion: protection with glutathione precursors. Neurotoxicology 26:1-8

14. Castoldi AF, Onishchenko N, Johansson C, Coccini T, Roda E, Vahter M, Ceccatelli S, Manzo L (2008) Neurodevelopmental toxicity of methylmercury: Laboratory animal data and their contribution to human risk assessment. Regul Toxicol Pharmacol 51:215-229

15. Hornig M, Chian D, Lipkin WI (2004) Neurotoxic effects of postnatal thimerosal are mouse strain dependent. Mol Psychiatry 9:833-845

16. Laurente J, Remuzgo F, Ávalos B, Chiquinta J, Ponce B, Avendaño R, Maya L (2007) Efectos neurotóxicos del timerosal, a dosis de vacuna, sobre el encéfalo y el desarrollo en hámsteres de 7 días de nacidos. Anales de la Facultad de Medicina Universidad Nacional Mayor de San Marcos (An Fac Med Lima) 68:222-237

17. Olczak M, Duszczyk M, Mierzejewski P, Bobrowicz T, Majewska MD (2010) Neonatal administration of thimerosal causes persistent changes in mu opioid receptors in the rat brain. Neurochem Res 35:1840-1847

18. Olczak M, Duszczyk M, Mierzejewski P, Wierzba-Bobrowicz T, Majewska MD (2010) Lasting neuropathological changes in rat brain after intermittent neonatal administration of thimerosal. Folia Neuropathol 48:258-269

19. Olczak M, Duszczyk M, Mierzejewski P, Meyza K, Majewska MD (2011) Persistent behavioral impairments and alterations of brain dopamine system after early postnatal administration of thimerosal in rats. Behav Brain Res 223:107-118

20. Hewitson L, Houser LA, Stott C, Sackett G, Tomko JL, Atwood D, Blue L, White ER (2010) Delayed acquisition of neonatal reflexes in newborn primates receiving a thimerosal-containing hepatitis B vaccine: influence of gestational age and birth weight. J Toxicol Environ Health A 73:1298-1313

21. Hewitson L, Lopresti BJ, Stott C, Mason NS, Tomko J (2010) Influence of pediatric vaccines on amygdala growth and opioid 
ligand binding in rhesus macaque infants: a pilot study. Acta Neurobiol Exp (Wars) 70:147-164

22. Baskin DS, Ngo H, Didenko VV (2003) Thimerosal induces DNA breaks, caspase-3 activation, membrane damage, and cell death in cultured human neurons and fibroblasts. Toxicol Sci 74:361-368

23. Ueha-Ishibashi T, Oyama Y, Nakao H, Umebayashi C, Nishizaki Y, Tatsuishi T, Iwase K, Murao K, Seo H (2004) Effect of thimerosal, a preservative in vaccines, on intracellular $\mathrm{Ca} 2+$ concentration of rat cerebellar neurons. Toxicology 195:77-84

24. Yel L, Brown LE, Su K, Gollapudi S, Gupta S (2005) Thimerosal induces neuronal cell apoptosis by causing cytochrome $\mathrm{c}$ and apoptosis-inducing factor release from mitochondria. Int J Mol Med 16:971-977

25. Zieminska E, Toczylowska B, Stafiej A, Lazarewicz JW (2010) Low molecular weight thiols reduce thimerosal neurotoxicity in vitro: modulation by proteins. Toxicology 276:154-163

26. Mutter J, Naumann J, Schneider R, Walach H, Haley B (2005) Mercury and autism: accelerating evidence? Neuro Endocrinol Lett 26:439-446

27. Young H, Geier D, Geier M (2008) Thimerosal exposure in infants and neurodevelopmental disorders: an assessment of computerized medical records in the vaccine safety datalink. J Neurol Sci 271:110-118

28. Gallagher C, Goodman M (2008) Hepatitis B triple series vaccine and developmental disability in US children aged 1-9 years. Toxicol Environ Chem 90:997-1008

29. Gallagher CM, Goodman MS (2010) Hepatitis B vaccination of male neonates and autism diagnosis, NHIS 1997-2002. J Toxicol Environ Health A 73:1665-1677

30. Bakir F, Rustam H, Tikriti S, Al-Damluji SF, Shihristani H (1980) Clinical and epidemiological aspects of methylmercury poisoning. Postgrad Med J 56:1-10

31. Eto K, Yasutake A, Kuwana T, Korogi Y, Akima M, Shimozeki T, Tokunaga H, Kaneko Y (2001) Methylmercury poisoning in common marmosets-a study of selective vulnerability within the cerebral cortex. Toxicol Pathol 29:565-573

32. Albrecht J, Matyja E (1996) Glutamate: a potential mediator of inorganic mercury neurotoxicity. Metab Brain Dis 11:175-184

33. Aschner M, Yao CP, Allen JW, Tan KH (2000) Methylmercury alters glutamate transport in astrocytes. Neurochem Int 37: 199-206

34. Allen JW, Mutkus LA, Aschner M (2001) Mercuric chloride, but not methylmercury, inhibits glutamine synthetase activity in primary cultures of cortical astrocytes. Brain Res 891: $148-157$

35. Juárez BI, Martínez ML, Montante M, Dufour L, García E, Jiménez-Capdeville ME (2002) Methylmercury increases glutamate extracellular levels in frontal cortex of awake rats. Neurotoxicol Teratol 24:767-771

36. Corpéchot C, Robel P, Axelson M, Sjövall J, Baulieu EE (1981) Characterization and measurement of dehydroepiandrosterone sulfate in rat brain. Proc Natl Acad Sci USA 78:4704-4707

37. Baulieu EE, Robel P (1998) Dehydroepiandrosterone (DHEA) and dehydroepiandrosterone sulfate (DHEAS) as neuroactive neurosteroids. Proc Natl Acad Sci USA 95:4089-4091

38. Majewska MD, Demirgören S, Spivak CE, London ED (1990) The neurosteroid dehydroepiandrosterone sulfate is an allosteric antagonist of the GABAA receptor. Brain Res 526:143-146

39. Majewska MD (1995) Neuronal actions of dehydroepiandrosterone. Possible roles in brain development, aging, memory, and affect. Ann NY Acad Sci 29:111-120

40. Monnet FP, Mahé V, Robel P, Baulieu EE (1995) Neurosteroids, via sigma receptors, modulate the $[3 \mathrm{H}]$ norepinephrine release evoked by $\mathrm{N}$-methyl-D-aspartate in the rat hippocampus. Proc Natl Acad Sci USA 92:3774-3778
41. French-Mullen JM, Spence KT (1991) Neurosteroids block Ca2+ channel current in freshly isolated hippocampal CA1 neurons. Eur J Pharmacol 202:269-272

42. Mao X, Barger SW (1998) Neuroprotection by dehydroepiandrosterone-sulfate: role of an NFkappaB-like factor. Neuroreport 9:759-763

43. Lapchak PA, Chapman DF, Nunez SY, Zivin JA (2000) Dehydroepiandrosterone sulfate is neuroprotective in a reversible spinal cord ischemia model: possible involvement of GABA (A) receptors. Stroke 31:1953-1956

44. Leskiewicz M, Jantas D, Budziszewska B, Lason W (2008) Excitatory neurosteroids attenuate apoptotic and excitotoxic cell death in primary cortical neurons. J Physiol Pharmacol 59: 457-475

45. Paxinos G, Watson C (1982) The rat brain in stereotaxic coordinates. Academic Press, San Diego

46. Rowley HL, Martin KF, Marsden CA (1995) Determination of in vivo amino acid neurotransmitters by high performance liquid chromatography with ophthalaldehyde-sulphite derivatisation. Neurosci Methods 57:93-99

47. Burba P, Willmer PG (1983) Cellulose: a biopolymeric sorbent for heavy-metal traces in waters. Talanta 30:381-383

48. Kapoor V, Nakahara D, Blood RJ, Chalmers JP (1990) Preferential release of neuroactive amino acids from the ventrolateral medulla of the rat in vivo as measured by microdialysis. Neuroscience 37:187-191

49. Brookes N, Kristt DA (1989) Inhibition of amino acid transport and protein synthesis by $\mathrm{HgCl} 2$ and methylmercury in astrocytes: selectivity and reversibility. J Neurochem 53:1228-1237

50. Reynolds JN, Racz WJ (1987) Effects of methylmercury on the spontaneous and potassium-evoked release of endogenous amino acids from mouse cerebellar slices. Can J Physiol Pharmacol 65: 791-798

51. Greenamyre JT (1986) The role of glutamate in neurotransmission and in neurologic disease. Arch Neurol 43:1058-1063

52. Choi DW (1988) Glutamate neurotoxicity and diseases of the nervous system. Neuron 1:623-634

53. Fitsanakis VA, Aschner M (2005) The importance of glutamate, glycine, and gamma-aminobutyric acid transport and regulation in manganese, mercury and lead neurotoxicity. Toxicol Appl Pharmacol 204:343-354

54. Makani S, Gollapudi S, Yel L, Chiplunkar S, Gupta S (2002) Biochemical and molecular basis of thimerosal-induced apoptosis in T cells: a major role of mitochondrial pathway. Genes Immun 3:270-278

55. Ueha-Ishibashi T, Oyama Y, Nakao H, Umebayashi C, Hirama S, Sakai Y, Ishida S, Okano Y (2005) Flow-cytometric analysis on cytotoxic effect of thimerosal, a preservative in vaccines, on lymphocytes dissociated from rat thymic glands. Toxicol In Vitro 19:191-198

56. Humphrey ML, Cole MP, Pendergrass JC, Kiningham KK (2005) Mitochondrial mediated thimerosal-induced apoptosis in a human neuroblastoma cell line (SK-N-SH). Neurotoxicology 26: 407-416

57. Geier DA, King PG, Geier MR (2009) Mitochondrial dysfunction, impaired oxidative-reduction activity, degeneration, and death in human neuronal and fetal cells induced by low-level exposure to thimerosal and other metal compounds. Toxicol Environ Chem 91:735-749. doi:10.1080/02772240802246458

58. Migdal C, Foggia L, Tailhardat M, Courtellemont P, Haftek M, Serres M (2010) Sensitization effect of thimerosal is mediated in vitro via reactive oxygen species and calcium signaling. Toxicology 274:1-9

59. Sokol PP, Holohan PD, Ross CR (1986) Essential disulfide and sulfhydryl groups for organic cation transport in renal brushborder membranes. J Biol Chem 261:3282-3287 
60. Denny MF, Atchison WD (1996) Mercurial-induced alterations in neuronal divalent cation homeostasis. Neurotoxicology 17:47-61

61. Mutkus L, Aschner JL, Syversen T, Shanker G, Sonnewald U, Aschner M (2005) In vitro uptake of glutamate in GLAST- and GLT-1-transfected mutant CHO-K1 cells is inhibited by the ethylmercury-containing preservative thimerosal. Biol Trace Elem Res 105:71-86

62. Sirois JE, Atchison WD (1996) Effects of mercurials on ligandand voltage-gated ion channels: a review. Neurotoxicol 17:63-84

63. Rodier PM (1995) Developing brain as a target of toxicity. Environ Health Perspect 103:73-76

64. Miyamoto K, Nakanishi H, Moriguchi S, Fukuyama N, Eto K, Wakamiya J, Murao K, Arimura K, Osame M (2001) Involvement of enhanced sensitivity of $N$-methyl-D-aspartate receptors in vulnerability of developing cortical neurons to methylmercury neurotoxicity. Brain Res 901:252-258

65. Costa LG, Aschner M, Vitalone A, Syversen T, Soldin OP (2004) Developmental neuropathology of environmental agents. Annu Rev Pharmacol Toxicol 44:87-110

66. Alcántara R, López-Corcuera B, Aragón C (1991) Group-selective reagent modification of the sodium- and chloride-coupled glycine transporter under native and reconstituted conditions. Biochim Biophys Acta 1067:64-70

67. Parra LA, Baust T, El Mestikawy S, Quiroz M, Hoffman B, Haflett JM, Yao JK, Torres GE (2008) The orphan transporter Rxt1/NTT4 (SLC6A17) functions as a synaptic vesicle amino acid transporter selective for proline, glycine, leucine, and alanine. Mol Pharmacol 74:1521-1532

68. Levi G, Bernardi G, Cherubini E, Gallo V, Marciani MG, Stanzione P (1982) Evidence in favor of a neurotransmitter role of glycine in the rat cerebral cortex. Brain Res 236:121-131

69. Tiedje KE, Stevens K, Barnes S, Weaver DF (2010) Beta-alanine as a small molecule neurotransmitter. Neurochem Int 57:177-188

70. Kilb W, Ikeda M, Uchida K, Okabe A, Fukuda A, Luhmann HJ (2002) Depolarizing glycine responses in Cajal-Retzius cells of neonatal rat cerebral cortex. Neuroscience 112:299-307
71. Thomson AM (1990) Glycine is a coagonist at the NMDA receptor/channel complex. Prog Neurobiol 35:53-74

72. Charalampopoulos I, Remboutsika E, Margioris AN, Gravanis A (2008) Neurosteroids as modulators of neurogenesis and neuronal survival. Trends Endocrinol Metab 19:300-307

73. Juhász-Vedres G, Rózsa E, Rákos G, Dobszay MB, Kis Z, Wölfling J, Toldi J, Párducz A, Farkas T (2006) Dehydroepiandrosterone sulfate is neuroprotective when administered either before or after injury in a focal cortical cold lesion model. Endocrinology 147:683-686

74. Kimonides VG, Khatibi NH, Svendsen CN, Sofroniew MV, Herbert J (1998) Dehydroepiandrosterone (DHEA) and DHEAsulfate (DHEAS) protect hippocampal neurons against excitatory amino acid-induced neurotoxicity. Proc Natl Acad Sci USA 95: 1852-1857

75. Selye H (1970) Mercury poisoning: prevention by spironolactone. Science 169:775-776

76. Szabo S, Gagnon MJ (1983) The protective effect of sulfurcontaining steroids against nephrocalcinosis induced by mercuric chloride in rats. Gen Pharmacol 14:269-272

77. Lao L, Franklin RB, Costello LC (1993) High-affinity L-aspartate transporter in prostate epithelial cells that is regulated by testosterone. Prostate 22:53-63

78. Butchbach ME, Tian G, Guo H, Lin CL (2004) Association of excitatory amino acid transporters, especially EAAT2, with cholesterol-rich lipid raft microdomains: importance for excitatory amino acid transporter localization and function. J Biol Chem 279:34388-34396

79. Geier DA, Geier MR (2007) A prospective assessment of androgen levels in patients with autistic spectrum disorders: biochemical underpinnings and suggested therapies. Neuro Endocrinol Lett 28:565-573 